\title{
What are you waiting to invest? Long-term investment in grid-connected residential solar energy in California. A real options analysis.
}

\author{
Marc Chesney and Carlos Vargas* \\ Department of Banking and Finance \\ University of Zurich \\ Switzerland
}

August 8, 2018

\begin{abstract}
The goal of this paper is to assess the optimal choice of a household in California, United States, in terms of their decision if and when to undertake a certain investment in a residential scale, grid connected, solar photo-voltaic system, in order to obtain savings in their monthly expenditures in electricity. This irreversible option is then defined, mainly, by the initial cost of the solar PV system. For this purpose, Real Options Analysis is deployed to assess this investment opportunity for the household. This approach allows determining not only whether the investments should be undertaken or not, but also the optimal timing to do so. Results show it is optimal for a Californian household to invest in a photo-voltaic system, however some delay might be advised depending on the energy production factor of specific areas, and the expected useful life of the equipment. Furthermore, government intervention influencing subsidies and energy prices has a bigger effect in the length such delays and should be avoided whenever possible.

Keywords: Renewable Energy; Real Options; Investments under uncertainty; Photo voltaic systems; Solar PV; Renewables
\end{abstract}

*carlos.vargas@bf.uzh.ch 


\section{Introduction}

The state of California accounts for close to half of the Solar energy capacity of the United States. With over 39 million inhabitants, California also comprises for onetenth of the population of the United States and drives an economy of over $\$ 2.3$ Trillion U.S. Dollars. The GDP for the state grew more than that of United States in 2017, and in comparison to U.S. GDP per capita, the same measure also shows significantly higher at the state level. As some experts suggest, adoption of solar energy at residential solar photo-voltaic (PV) energy is still scarce in the rest of the United States, but not in California, with over 6.18 million $\mathrm{kW}^{1}$ of PV installed. 92\% of all PV projects reported in the U.S. are claimed to be residential, close to $97.15 \%$ of all PV projects in California (over 3.74 million $\mathrm{kW}$ of the installed PV in the state) are as well residential. How can the boom of residential solar PV projects in California be explained? Is it worth investing in residential solar PV projects in this state? And if so, is it still optimal to invest there in view of current market prices of electricity, investment cost and expected technological advancements in the foreseeable future?

Real option assessment (ROA) models are a great fit to identify optimal stopping time problems, such as the one stated in the above questions. These models are used in order to check whether investment decisions should be taken and when is the optional time to do so. Besides these models, the standard tool used in this setting before was time value of money, and particularly, Net Present Value (NPV). This methodology, an investment should be triggered if and only if its NPV, i.e. the difference between its expected discounted payoffs and costs is positive. The criteria for NPV is then static to the extent to which the choice is between realizing the investment at the date when the NPV is calculated, or never. This is a significant drawback of the NPV criterion.

In our case, the household has the right, and not the obligation, to make an investment during a given period of time and they are also given the possibility of postponing the investment, for up to 20 years in this case. The life-cycle of the given investment presented in this setting also accounts for up to 30 years, given the existing solar PV technology. When identifying the optimal investment date, the possibility of postponing it is also taken into account. An option also includes the economics of irreplaceable assets and stress that performing an irreversible action at one point in time involves the cost of renouncing the flexibility to wait; if this cost is correctly taken into account in a cost-benefit analysis, in order for the action to be economically justified, the benefits from the decision must be higher than in a traditional cost-benefit analysis.

Historically prices of PV panels in California are presented from self reported projects by their developers and/or investors. For the purpose of this study, only 122,859 of those records resulted relevant. Criteria for relevance including filtering only projects reported as Residential, that were appraised by third parties, had a range of cost between $\$ 10$ and $\$ 1,000,000$ USD, and an installed capacity ranging

\footnotetext{
${ }^{1}$ kilowatts
} 
between 1 and $30 \mathrm{~kW}$, in order to reduce noise. PV costs were retrieved from the OpenPV Database, that offers 1,020,672 records of solar installs in the United States. The OpenPV database offers the cleaner dataset "Tracking the Sun 10" (Barbose et al., 2017) that is published annually and provided more relevant observations. As selfdescribed by the National Renewable Energy Laboratory, "The Open PV Project is a collaborative effort between government, industry, and the public" and was a very complete source of historical data. This dataset is voluntarily contributed from a variety of sources, and while information available can be extensive it was not always relevant.

This paper includes an analysis on PV project data, residential energy prices and subsidies for PV energy at State level for California, but it could easily be scaled for data for other states in the country ${ }^{2}$. This paper can also be a baseline for new developments in the PV market, not only for residential solar energy but also for non-residential and utility-scale projects.

This paper is organized as follows: Section 1 gives an overview of the state of research in ROA, particularly for solar PV energy in California and the United States, including the current development of this technology, and also provides a general framework on historical prices of residential electricity, which are both relevant for our model. Section 2 gives an overview of the literature on research in ROA and in particular for the energy industry. Section 3 outlines the model and the numerical method used to solve our model and the choice of parameters. Section 4 introduces the case study of California and the variables used for the setting defined and our model assumptions. Section 5 gives the main results and the key findings in the sensitivity analyses of our results. Section 6 concludes.

\section{Literature Review}

A number of studies in the Economic literature have addressed solar PV projects. It has been in fact a recurring topic in academic journals over the last two decades and has covered different geographies, perhaps showing more regularity for the United States and western Europe. One early example can be found with Wiser (1997) that explores different ownership and financial structures for the investment on renewable energy (RE). Wiser mostly centers on utility scale wind energy projects, but even if his scope falls a bit outside of the scope of this paper, his conclusion clearly touches a sensitive assumption of this model, by affirming that costs can vary highly, up to $40 \%$ in his case, by the simple effect of changes in financing structure and ownership. Faiers and Neame (2006) present an interesting survey that shows among other things, that "The success of the UK policy to reduce carbon emissions is partly dependent on the ability to persuade householders to become more energy efficient" and by such affirmation establishes a clear relevance of solar energy in that country.

\footnotetext{
${ }^{2}$ Not all states report enough projects to the OpenPV project database in order to allow for a fair assessment.
} 
A couple years after Fouquet and Johansson (2008) introduce the two main forms of incentive systems to promote RE in the European Union (Feed-in-Tariffs and Tradable Green Certificates) by establishing that "a target for RE penetration is set by public authorities seeking to minimize cost for achieving this target." That in a way is still relevant today since RE projects pose the interesting potential for savings and reduced environmental impacts but still have a significant up-front cost. The authors of that article also highlight the preference of users to up to incentives as Feed-inTariffs (FiT) provided theirs in countries like Denmark, Germany, and Spain. Frondel et al. (2010) on the other hand, contradict the supposed success of the Feed-in-Tariff system implemented in Germany.

Dusonchet and Telaretti (2010) go a little bit further and assesses the economic potential of PV projects in different western European Union countries, and obtains interesting results in a comparison that shows some limitations of different incentive schemes implemented at national level. Results of the comparison presented are very complete, however the methodology for this paper bases the analysis on Time Value of Money that is a static valuation methodology. Klein and Deissenroth (2017) indicate that "Stepwise changes in the remuneration design can therefore induce non-linear and non-intended investment behavior" however the novel part of their analysis focusing on prospect theory, they apply their model to an NPV methodology. As mentioned by the authors "The value function of prospect theory. The disutility of losses is comparatively larger than the utility of gains of the same absolute size. The shape of the value function can be measured experimentally." Escribano et al. (2011) works with the "evolution of electricity prices in deregulated markets" and unveils interesting elements on how to deal with seasonality and mean reverting processes in energy. Bull et al. (2011) start to introduce the U.S. into the scope by analyzing the implementation of Feed-in-Tariff systems in California and New York. The authors also include analysis in the Reverse Action Mechanisms also implemented in California as a form of incentive, and stress the importance of such incentives to continue to promote the development of distributed RE at an adequate pace. Martin and Rice (2018) further go into the complexity of designing and implementing "a fair and reasonable retail FiT policy". They also evaluate the convenience on the level of government regulation on that matter and further discover that stakeholders perceptions on this matter end up being shaped geographically.

Drury et al. (2012) at once enter the southern Californias residential PV market by exploring its evolution through third-party ownership, and it continues to be a key component of such investments, however third party ownership can be perceived as a proxy for positive economic returns, since on rational investors would be involved in such a scheme. The authors suggest two very interesting finding, the former that third-party owned residential PV systems are rapidly growing when regulation allows for them, and the latter that at the time of that study, evidence suggests that reducing price barriers from $\$ 6$ to $\$ 4$ USD/Watt (after incentives in both cases), was not sufficient to attract new investments in PV systems. Something very interesting, considering the current situation of the market in California, as it is further described in this paper. Schelly (2014) reviews the phenomenon of early adopters of residen- 
tial solar PV projects. This study suggests three main points: "(1) environmental values alone are not enough and are not always necessary, to motivate adoption; (2) rational economic calculation in the narrow sense of calculated return on investment or payback period is less important than the particular timing of economic events within a household; and (3) perceiving oneself as an early adopter is only important for some, while communication through social networks occurs in the context of communities of information." In a way, Schelly's findings reinforce the importance of assessing uncertainty as a key component in the decision. A potential benefit then has to be perceived, but it in essence has to be, both, as certain and positive as possible. Wolske et al. (2017) find that although households in the United States perceive solar PV in a positive way: "as an environmental benefit, a consumer good, and an innovative technology" when promoting such investments to households, marketing efforts have to emphasize more on "non-environmental benefit" even for environmental concerned individuals. It still seems to be a hard sell.

Some authors even engage to compare PV project markets in Europe and the U.S., as Seel et al. (2014) provide evidence showing "Residential photovoltaic (PV) systems were twice as expensive in the United States as in Germany (median of $\$ 5.29 / \mathrm{W}$ vs. $\$ 2.59 / \mathrm{W}$ ) in $2012^{\prime \prime}$ which is quite a reveling finding. As some studies show, these findings do not contradict the clear reduction in price of the PV systems observed, but rather indicate that soft costs piling up into the total investment value of a system are key factors to consider. Wüstenhagen and Menichetti (2012) summarize strategic choices for RE investments. In particular one important aspect touching solar PV projects in recent years is the dramatic reduction on the cost of the systems, Candelise et al. (2013); Bazilian et al. (2013) present some work on different forecasting methods for PV system pricing. Pillai (2015) suggests that "the upstream industries that supply the solar panel industry with raw materials and capital equipment have been important contributors to the reduction in the production cost of solar panels" which can in a way contradict the popular believe that solar panel cost has reduced mainly on technological advancement and efficiency, but also allows to more conservative estimates for further assumptions on price reductions.

The general setting of this paper is based on the work of Bauner and Crago (2015) and Chesney et al. (2017) and establishes the benchmark of a typical household with an investment irreversible option to install a solar PV system. Although Bauner and Crago (2015) present an application only for the state of Massachusetts, their model of adoption of residential solar power under uncertainty is quite relevant to the scope of this work. These authors center their work on the implications of their finding over incentives. They "determine optimal adoption times, critical values of discounted benefits, and adoption rates over time for solar PV investments", which is in line with the objective of this paper. Their results reach that "policies that reduce the uncertainty in returns from solar PV investments would be most effective at incentivizing adoption." Their analysis is deep, and the methodology implemented by this authors is dynamic, allowing to better assess uncertainty in potential savings, which is quite novel, but their assessment of data for Massachusetts allowing them to state that "despite generous financial incentives the adoption rate is low." 
is not necessarily the case in California, which allows for further exploration in the most relevant solar PV market in the United States. Kim et al. (2017) also propose a ROA model to assess RE investment decisions in developing countries. They offer an application of ROA in developing countries which is quite novel, however, their analysis includes a binomial lattice for calculating compounded of options that, although dynamic, is rather simplified. Matisoff and Johnson (2017) explain that "Results suggest that approximately $67 \%$ of state and utility incentives, up to $\$ 1.9$ billion over 11 years, were likely spent on incentives that did not increase residential solar PV installations". Yet again it is clear that incentives are decreasing, but also that they are not implemented in the most efficient way.

Some studies like Luthander et al. (2015) explore the impact of self-consumption in several countries in a world of decreasing subsidies. They even go a step further and analyze the so called demand side management (i.e. energy storage and load management). Other studies like Kastner and Stern (2015) go even further and review 26 empirical studies on the decision-making processes behind household energy investments. Among their findings, perhaps the most relevant is their affirmation on the progress of behavioral research on this field. "About half the empirical studies we considered were completed during the past five years." Showing that this is still quite a novel field of research, but one obtaining major relevance at an increasing rate. Salm et al. (2016) explore the relation of risk-return preferences towards RE projects for retail investors in Germany. Among the findings of this study we can observe that opossed to professional investors, retail investors "use simple decision rules such as calculating payback time or relying on their gut feeling when making investment". Castellanos et al. (2017) explore the potential of Rooftop solar PV in cities. Vaishnav et al. (2017) explore the dramatic fall in subsidies in the United States in 2014, which is clearly consistent with our analysis. Krupa and Harvey (2017) goes into analyzing RE finance in the United States and determines the effect of subsidies which actually result in net financing rates that fall below the assumptions of this study. Mazzucato and Semieniuk (2018) probe financing renewable energy: Who is financing what and why it matters "Financial actors vary considerably in the composition of their investment portfolio, creating directions towards particular technologies. Public financial actors invest in portfolios with higher risk technologies, also creating a direction; they also increased their share in total investment dramatically over time."

On looking for further possibilities to enrich the scope of this we work, it can be mentioned that some work has been done on Real Option Analysis regarding climate change that could also be extrapolated to energy modeling. Chesney et al. (2017) elaborate on more on this are by introducing risk aversion in Real Options while assessing the optimal choices of a forest owner given his option to enter an irreversible scheme that provides uncertain cash flows under different risk aversion scenarios. This is in a way the same situation in which this paper is written, provided that households are also faced with the irreversible option to enter an investment with uncertain cash flows and perhaps within different risk aversion scenarios. For this paper the risk aversion of the investor is not relevant to their rational decision 
to invest or not in solar panels to obtain potential savings, but risk aversion could be nevertheless a great element to further explore within this setting in future work. Even more, considerations of game theory and competition could also be included to asses competition in such a dynamic market as California; Botteron et al. (2003) propose a model that could also be adapted to that purpose. Finally another important aspect to consider when talking about solar PV energy is storage. Besides the entry barriers already highlighted, production intermittency is the other key challenge to solve. Hoppmann et al. (2014) discuss this through a simulation, which could also be included in a further extension of this research. Futhermore, Rai and Robinson (2015) incorporate the integration of social, behavioral, economic, and environmental factors in a model of energy technology adoption. This could also be a nice to have in further work. Ng and Tao (2016) present different schemes to promote renewable energy financing in Asia though bonds. This aiming to the financing gap for renewable energy. Lam and Law (2016) go beyond to establish green financing schemes for renewable and sustainable energy projects through Crowd-funding. Potential financing alternatives seem to be attractive also to assess on further work.

\section{Model and Numerical Methods}

The present study describes some basic properties of the ROA aiming to increase and apply the methodology to assess savings for households, while taking advantage and deciding the optimal investment time. This is done specifically for the case of a typical house in California. The general setting of this paper is based on the work of Bauner and Crago (2015); Chesney et al. (2017) and establishes the benchmark of a typical household with an investment irreversible option to install a solar PV system. The household is assumed to minimize their cost of energy $k$, and faces a trade-off between expected savings and the initial investment cost of investing, given that the invest amount is known, while the energy price is uncertain. The household decision-maker is assumed to be rational. The investment decision can be triggered any time $\tau_{A}$ (from now to the next 20 years).

The household then has a benchmark opportunity (Business as usual or $B a U$ ) to obtain their full electricity supply from the grid, or alternatively, the option $A$ to invest in solar PV system, that would allow them to obtain potential savings in the long run for as many as 30 years ${ }^{3}, \tau_{A}+20$ or $\tau_{A}+30$, provided that the household implements the stated irreversible option $A$. Grid interconnectedness also allow to efficient disposition of the totality of the energy produced. The BaU scenario is defined by:

$$
k_{t}^{B a U}=P_{t} Q
$$

Under option $A$, if electricity prices increase, the potential savings are high, and

\footnotetext{
${ }^{3}$ A typical project offers an expected savings horizon of up to 30 years, given the current state of development lifespan of solar PV technologies.
} 
vice-versa. The potential amount of electricity to be produced by the named solar PV system is defined by the energy production factor, $\phi$, see Figure 8 in the Appendix. Since we focus on potential savings, after undertaking the investment option, the household expenditures on electricity are no longer relevant ${ }^{4}$, and would then be only defined the cost of energy not produced by the investment which theoretically would be seamless, assuming the household is self-sufficient to supply their energy requirement with the installed PV system. This equation also includes the possibility of some operational or financial cost over time $C_{t}$, i.e. in case the project obtains third-party financing, or requires additional variable cost considerations.

$$
k_{t}^{A}=\phi P_{t} Q-C_{t}
$$

For equations 1 and 2, $P_{t}$ is the time t price of electricity, $Q$ is the fixed amount of energy produced and consumed by the household. The expected total revenue, or total savings, of such household, then results from the savings that can be directly observed from that investment. The difference between the energy costs of the two scenarios, with and without solar PV energy production can then be defined by $\Omega$ in equation 4 . This equation also includes the net amount of the initial investment, further defined as $I_{t}$ in equation 3 , where $I_{t}>0$. This amount adds the installation $\operatorname{cost} N_{t}$, a potential subsidy or rebate to be received by the project $S$, and a potential reduction of the initial capital disbursement $F$ in case of third-party financing is obtained for the project.

$$
I_{t}=N-S-F .
$$

In equation 4 the first righthand side term is the total cost of energy over 20 periods of time without solar, and the second term is the net cost of energy with the solar PV system (including the investment). For the household, if $\Omega \geq 0$, total energy cost is lower with the installation of solar panels.

$$
\Omega=N P V=\mathbb{E}\left[\sum_{\tau_{A}}^{\tau_{A}+20} k_{t}^{A} e^{-r t}-I_{\tau_{A}} e^{-r \tau_{A}}\right]
$$

The household will decide when to invest in the option, aiming to maximize their total expected future savings:

$$
\max _{\tau_{A}} \Omega
$$

Now, the household not only has the possibility to invest or not invest in such option, but also has the option to delay the investment. Under this setting, the traditional NPV criteria would no longer hold for the household, and even if potential savings exist at a certain point, given that delays cannot be captured by NPV. And so the household could choose to defer the investment, even infinitely.

\footnotetext{
${ }^{4}$ Unless fixed monthly charges for residential electricity are introduced in California.
} 
Both $P_{t}$ and $N_{t}$ are stochastic. The former follows a geometric Brownian motion ${ }^{5}$ and the latter follows an Arithmetic Brownian Motion ${ }^{6}$ as defined below:

$$
\begin{aligned}
& d P_{t}=\alpha_{1} d P_{t} d t+\sigma_{1} P_{t} d B_{t} \\
& d N_{t}=\alpha_{2} N_{t} d t+\sigma_{2} N_{t} d W_{t}
\end{aligned}
$$

Where both $B_{t}$ and $W_{t}$ are Wiener processes that follow a normal distribution with zero mean and variance, and the drift and the volatility are defined by $\alpha_{n}$ and $\sigma_{n}$ respectively. We also assume that no correlation exists between $B_{t}$ and $W_{t}$ since the underlying of both processes are independent, one relying on the prices of electricity and the other on the dynamics of pricing of solar panels.

\subsection{Assumptions regarding the model variables}

There are two major Assumptions regarding the model variables. On one hand, the price of residential electricity is one important variable for our model, especially when observing its evolution over time. To model the price dynamics, we rely on the historical distribution of residential electricity as provided by the U.S. Energy Information Administration (EIA). Prices denote important seasonality and volatility that had to be modeled accordingly. On the other hand, cost of investment in solar PV technology has observed a very particular trend of unprecedented reduction, in parallel of technology advancement on energy production. In other words, solar PV technology has become and is expected to increasingly be cheaper and more efficient than it historically was.

Finally, an important goal of the paper is to broaden and deepen the discussion on real option models dealing with multiple options simultaneously, also known as a portfolio of options, while assessing the benefit of revenue increase for households which has in the past been limited to stressing the advantages of the technique rather than reflecting on specific applicability and application of the methodology. It is also innovative to apply this methodology for this particular setting and region. In fact, although solar PV projects have been a recurring topic in the assessment of different Economic Studies, Real Options Analysis has only been applied to other regions and it has been much limited to a handful of studies published several years ago, which means that these studies do not include current price conditions.

\subsubsection{Price of the PV panels in California}

In terms of the investment decision assessed in this paper, the main component of cost is determined by the initial investment on a residential scale, grid connected, solar photo-voltaic system ${ }^{7}$ in order to obtain savings in their monthly expenditures

\footnotetext{
${ }^{5}$ For a geometric Brownian motion, the drift $\alpha_{1}$ and the volatility $\sigma_{1}$ are expressed in USD returns.

${ }^{6}$ For an arithmetic Brownian motion, the drift $\alpha_{2}$ and the volatility $\sigma_{2}$ are expressed in USD.

${ }^{7}$ For further reference, see Figure 7 in the Appendix.
} 
in electricity. It is common belief that the cost of solar panels has been reducing for the last decade, and also that technology has improved to a current point of efficiency that has reduced the unitary investment cost in solar panels. Which is in fact true. However, for the scope of this study, the initial investment assessed does not only include the cost of the panels but actually the real investment cost reported on PV projects installed in the state over the last decade, which have also declined as it will be explained below. Overall investment cost reductions, in any case, have also triggered debate on the convenience to give continuity to the incentives for solar investment available in the state for many years. This work addresses both of those components in our estimates.

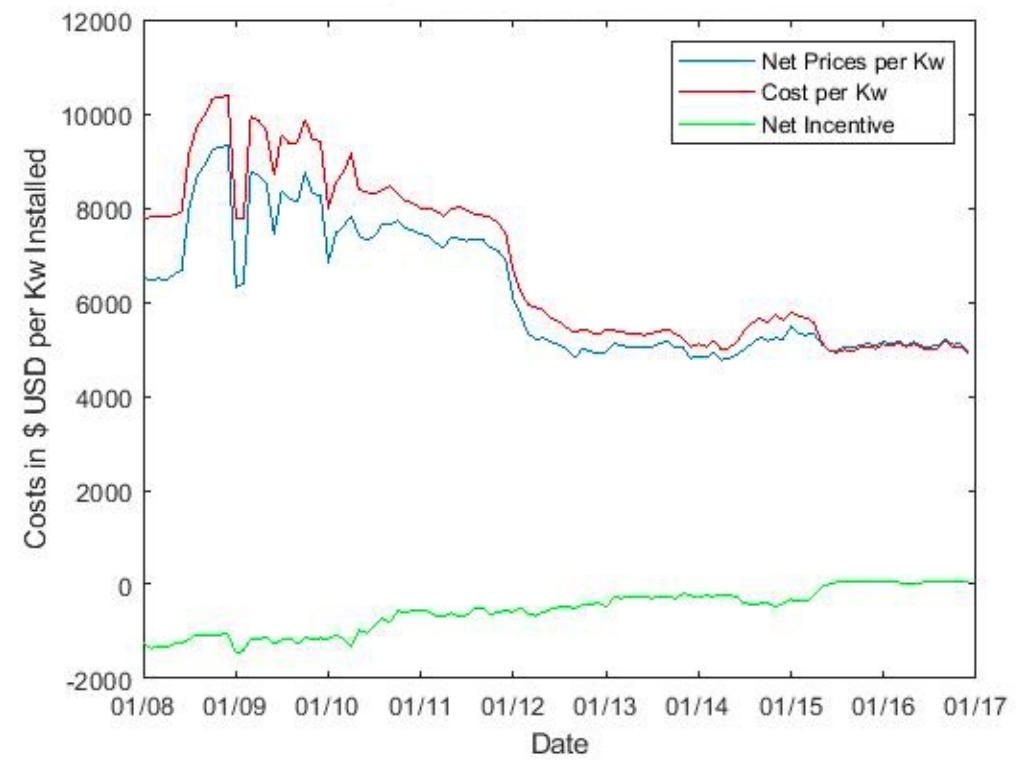

Figure 1: Historical cost of PV Panel Systems by kW in California, own illustration. (Barbose et al., 2017)

As we can observe Figure 1, for costs in USD per $\mathrm{kW}$ installed, historical data shows very interesting trends on the cost of investments in PV between 2008 and 2016. In this figure we can observe three distinct lines, the red line portraying the Cost of PV systems as reported by the installer and excluding any incentives or subsidies. The blue line shows the same investment cost including the effect of incentives or subsidies, in case they were obtained and so is described as the Net Price per $\mathrm{kW}$ of the system. Lastly, the green line shows the amount of any reported incentive or subsidy.

Here we can observe two important trends. First, prices of PV systems are, in fact, declining over time, while the use of incentives or subsidies has also reduced. Since incentives or subsidies reduce the investment amount of households investing in solar PV systems, and it is always optimal to use as much of incentives as possible, then it can then be inferred that this reduction is likely motivated by the availability 
of such incentives or subsidies. However, the reduction of net investment cost in PV systems seemed very pronounced between 2010 and 2012, it becomes is quite flat after 2015. And finally, we can also notice that the net effect of incentives and subsidies is very close to zero after mid 2015.

Figure 2 captures these estimates and shows on the left side, the historical data decribed before, and on the right side different paths of estimations based on that data. It can be observed that the paths not only allow for further reduction in price but also show some expected increases (as shown historically) and seem to be quite flat in average for the period estimated.

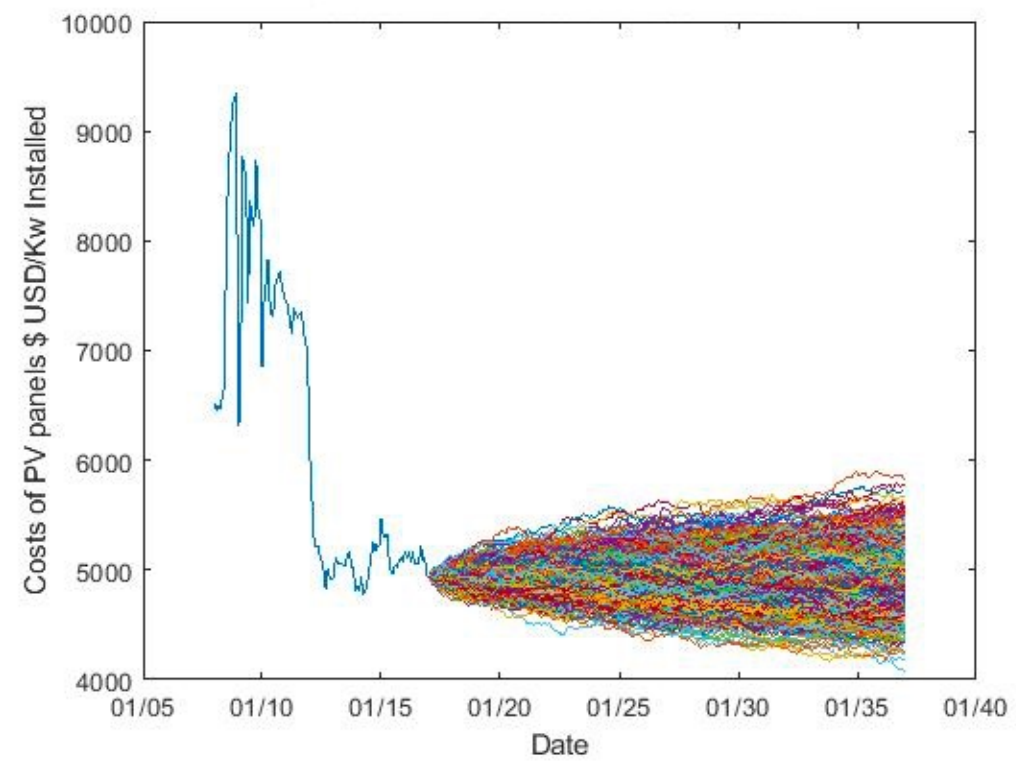

Figure 2: Actual and simulated cost of PV Panel Systems to residential customers in California per $\mathrm{kW}$ Installed, own illustration.

(U.S. Department of Energy, 2016)

Further detail on a single path of the estimation and the agregate trend of 300 paths can be observed in figures 9 and 10 in the Annex.

\subsubsection{Energy residential price dynamics in California}

Energy prices used for the calibration of this model include monthly average data from January 2001 until December 2017. For the dynamics of prices in California we can clearly identify three important trends: first, a clear increase curve overtime for historical prices, second, an expected seasonality that is marked in figure 3(b) in red, and third, sound negative jumps in the price trends every six months, starting in April 2014, accounting for approximately $-70.4 \%$ and $-79.68 \%$, for April and October respectively, to the expected value of such values assuming they did not exist. For the simulation of energy prices, we account for all three trends in order to obtain a more accurate result. 

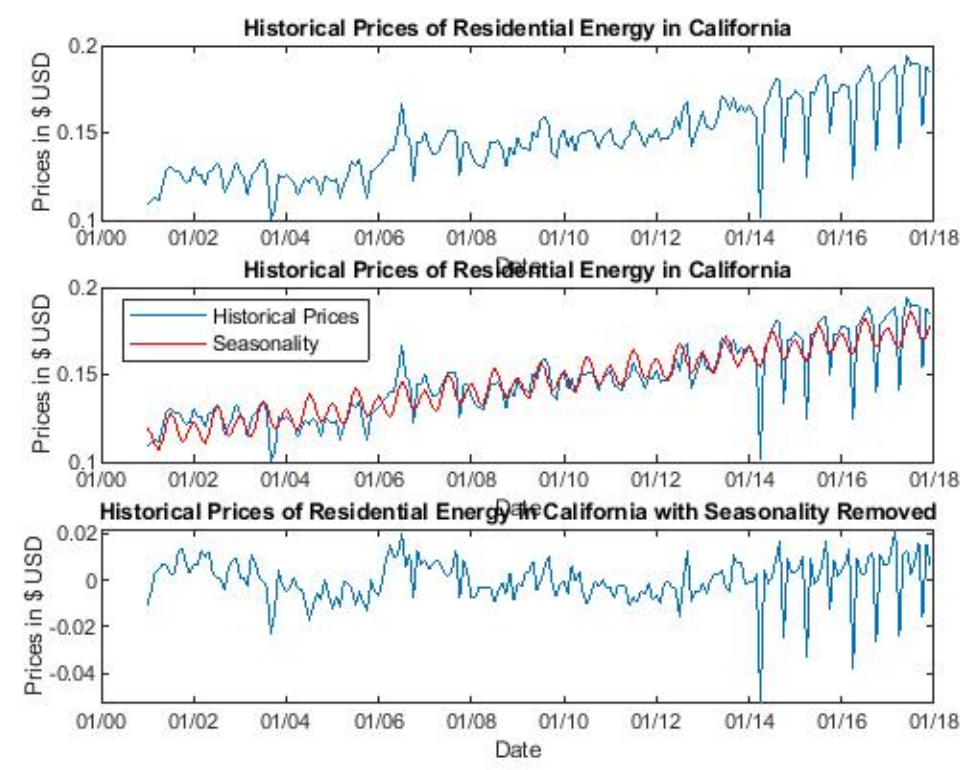

Figure 3: Historical electricity rates to residential customer in California, own illustration.

(U.S. Energy Information Administration, 2018)

Historical energy prices were retrieved from the U.S. Energy Information Administration, Form EIA-861M (formerly EIA-826), Monthly Electric Power Industry Report. U.S. Energy Information Administration (2018). Ultimately all data analyzed in this paper was obtained from public databases of the U.S. Department of Energy, which resulted to be extremely relevant for the analysis presented in this paper.

Energy residential rates in the state of California show three very clear trends seasonality, increase overtime and identifiable recurrent negative jumps. Seasonality, as mentioned above, is addressed on this model by subtracting it before the calibration of the model and adding it back to be accurately reflected in the simulations. The increasing trend is easily replicated by the process chosen for the estimation. Lastly, the negative jumps are also adjusted every 6 months, according to their prevalence since 2014. 


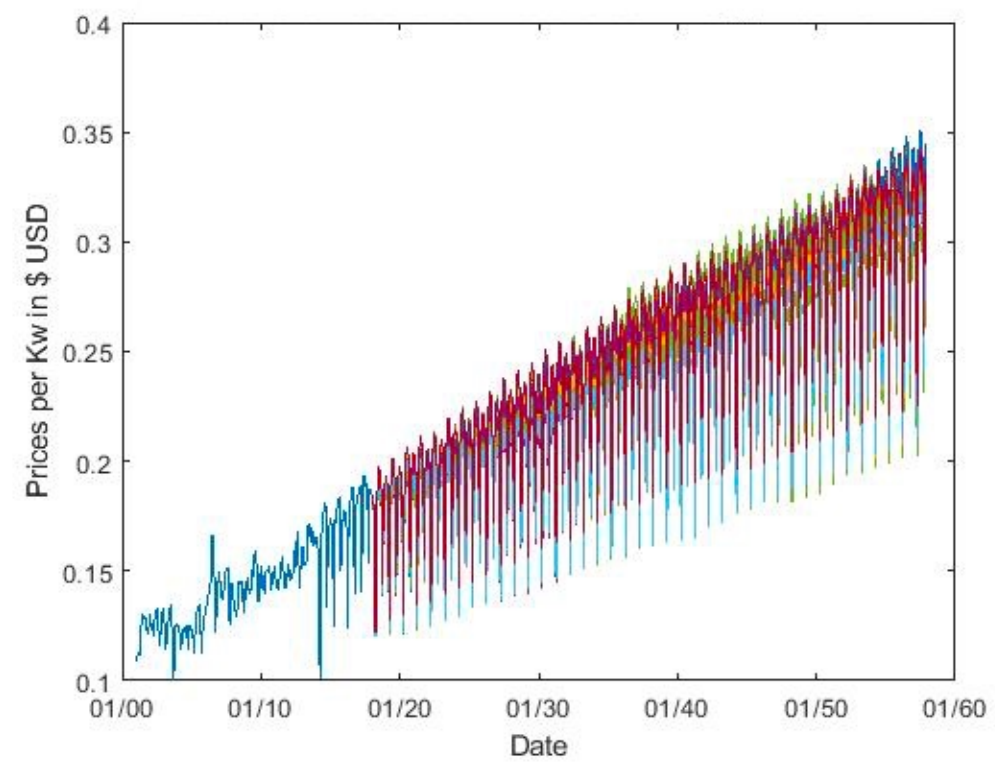

Figure 4: Actual and simulated electricity rates to residential customers in California, own illustration.

(U.S. Energy Information Administration, 2018)

Further detail on a single path of the estimation and the agregate trend of 300 paths can be observed in figures 11 and 12 in the Annex.

\section{Case Study and Altenative Option}

The case study considered in this case is the one of a typical household in California. Based on the chosen parameters, the households' optimal decision shows savings that solely come from the installment of the PV system. The detail on the parameters used for the model calibration can be found in Table 1 below.

Table 1: Model calibration parameters.

\begin{tabular}{ccccc}
\hline Parameter & Explanation & Value & Sensitivity Analysis & Sources \\
\hline$I_{t}$ & Initial investment cost & $\$ 5,055 \mathrm{USD} / \mathrm{kWh}$ & see Figure 2 & (Barbose et al., 2017) \\
$P_{t}(0)$ & Residential energy rate & $\$ 0.1848 \mathrm{USD}$ & see Figure 11 & $\begin{array}{c}\text { (U.S. Energy Information Administration, 2018) } \\
\text { Own calculation, (Barbose et al., 2017) }\end{array}$ \\
$Q$ & Installed PV capacity & $5.5519 \mathrm{~kW}$ & - & (U.S. Department of Energy, 2016) \\
$\phi$ & Energy production factor & $1,900 \mathrm{kWh} /$ year & {$[1,710 ; 2,090]$} & - \\
$C_{t}$ & Variable cost & 0 & - & - \\
$\tau_{A}$ & Starting point of the investment & - & - & Own calculation \\
$\alpha_{1}$ & Drift of energy rates & $1.50 \mathrm{E}-17$ & - & Own calculation \\
$\sigma_{1}$ & Volatility of energy rates & 0.009773012 & - & Own calculation \\
$\alpha_{2}$ & Drift returns of PV costs & -0.002580 & - & Own calculation \\
$\sigma_{2}$ & Volatility returns of PV costs & 0.064289 & - & Own, based on HELOC Interest Rate \\
$i$ & Discount rate & 0.004808 & - & - \\
$d t$ & Time steps & $1 / 360$ & & \\
\hline
\end{tabular}

As mentioned above, the household has two alternatives: Business as usual, the 
benchmark case, or "do nothing!" or an alternative option, to invest in a PV System. The former offers no perceived benefit on savings from the perspective of the household since they are assumed to consume a given amount of energy for the time considered in the present study. The latter, however, allows the household to obtain certain savings provided that they invested in a PV system that satisfies their consumption. All energy produced and consumed by the household is assumed to be equal in the presence of net metering in a grid connected system ${ }^{8}$, meaning that they either consume as much energy as they produce or they save it by supplying any excess of production to the grid to consume it in the future. The household is also assumed to either consume the energy produced (and any energy saved on the grid) during the length of the scope of this analysis in order to perceive such benefits.

\section{Results}

\subsection{Alternative option: Invest in a PV System}

In the presence of boundaries limiting their maximum possible saving, the household faces an important irreversible decision: to invest in a solar PV system or not. As we can observe in figure 5, for the area $\mathrm{EPF}=1,900$ we can observe how this decision is located between now and waiting to invest for 12 more years. This describes how uncertain the decision scenarios for the household are. In the benchmark case even, the decision for this area would have to be delayed approximately 4 years, perhaps another drawback to driving investment.

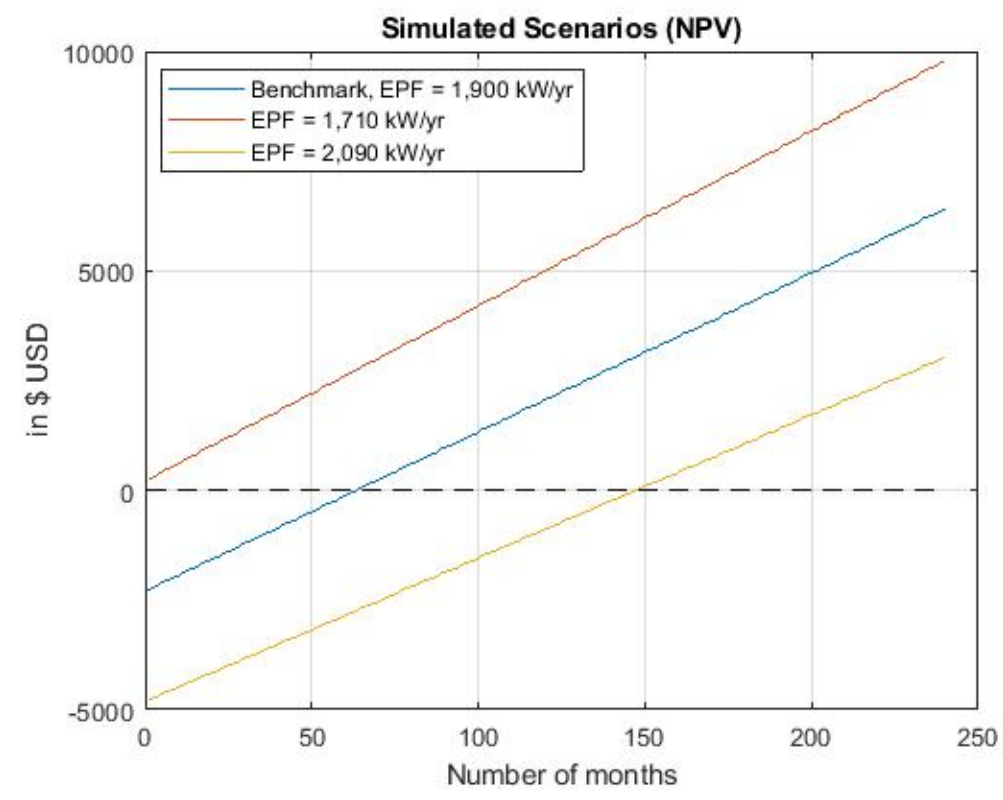

Figure 5: Simulated EPF Scenarios, own illustration

\footnotetext{
${ }^{8}$ For further reference see figure 7 Appendix.
} 


\subsection{Sensitivity Analysis}

As we can observe in figure 6 and table 2 different energy production factors along the state of California result in different expected delays for the investment. Areas with the most EPF clearly seem to suggest more immediate investment, while areas with the least EPF even suggest avoiding the investment ${ }^{9}$.

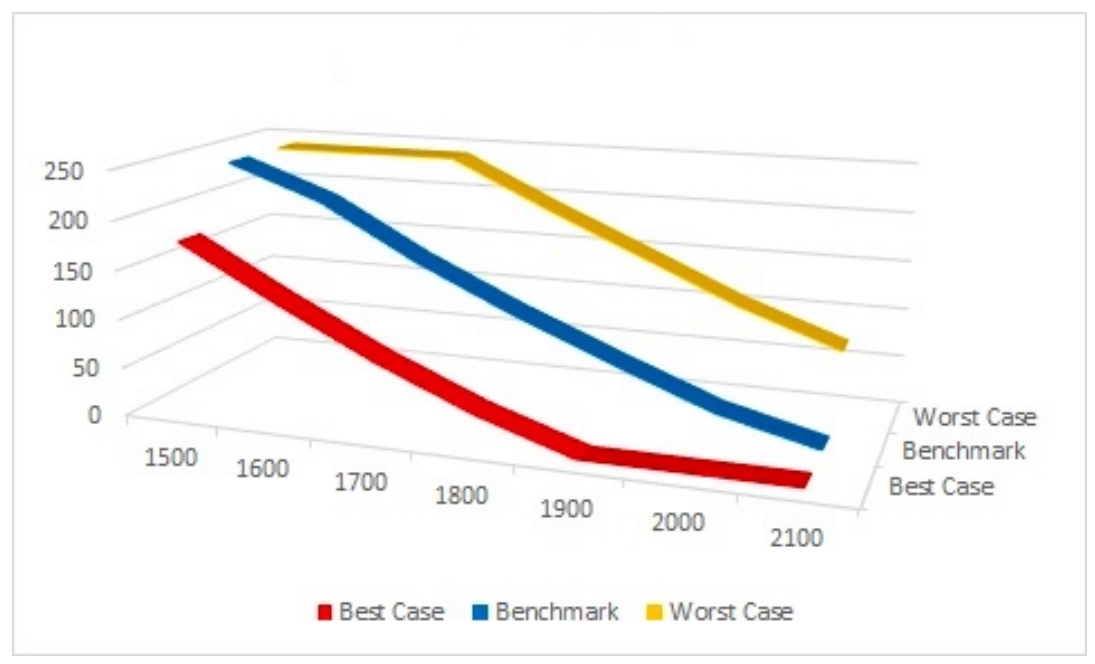

Figure 6: Multiple EPF scenarios of stopping times, own illustration

Table 2: Expected Optimal Time to invest in PV system with an estimated useful life of 20 years (in number of months).

\begin{tabular}{cccccccc}
\hline Scenario & $\mathbf{1 , 5 0 0}$ & $\mathbf{1 , 6 0 0}$ & $\mathbf{1 , 7 0 0}$ & $\mathbf{1 , 8 0 0}$ & $\mathbf{1 , 9 0 0}$ & $\mathbf{2 , 0 0 0}$ & $\mathbf{2 , 1 0 0}$ \\
\hline Best Case $(+10 \%)$ & 177 & 124 & 75 & 33 & 0 & 0 & 0 \\
Benchmark & $\infty$ & 205 & 151 & 105 & 64 & 25 & 0 \\
Worst Case $(-10 \%)$ & $\infty$ & $\infty$ & $\infty$ & 193 & 149 & 105 & 69 \\
\hline
\end{tabular}

Source: Own illustration

As we can observe in Table 3 in the best case scenario, of a project with an estimated useful life of 30 years, which is in fact achievable under current state of technology, we encounter significant improvements in the reduction of the investment delay, which immediate in several scenarios, but does not exceed 6 years in the benchmark case of any of the geographies nor 14 years in the the worst case scenario for the geogrphic area with the least energy production potential.

\footnotetext{
${ }^{9}$ For this setting, $\infty$ suggests that the evaluation did not find an optimal stopping time within 20 years.
} 
Table 3: Expected Optimal Time to invest in PV system with an estimated useful life of 30 years (in number of months).

\begin{tabular}{cccccccc}
\hline Scenario & $\mathbf{1 , 5 0 0}$ & $\mathbf{1 , 6 0 0}$ & $\mathbf{1 , 7 0 0}$ & $\mathbf{1 , 8 0 0}$ & $\mathbf{1 , 9 0 0}$ & $\mathbf{2 , 0 0 0}$ & $\mathbf{2 , 1 0 0}$ \\
\hline Best Case $(+10 \%)$ & 0 & 0 & 0 & 0 & 0 & 0 & 0 \\
Benchmark & 72 & 21 & 0 & 0 & 0 & 0 & 0 \\
Worst Case $(-10 \%)$ & 159 & 104 & 55 & 12 & 0 & 0 & 0 \\
\hline
\end{tabular}

Source: Own illustration

\subsection{Other options}

Table 4: Expected Optimal Time to invest in PV system (in number of months) without the effect of negative jumps.

\begin{tabular}{cccccccc}
\hline Scenario & $\mathbf{1 , 5 0 0}$ & $\mathbf{1 , 6 0 0}$ & $\mathbf{1 , 7 0 0}$ & $\mathbf{1 , 8 0 0}$ & $\mathbf{1 , 9 0 0}$ & $\mathbf{2 , 0 0 0}$ & $\mathbf{2 , 1 0 0}$ \\
\hline Best Case $(+10 \%)$ & 143 & 91 & 44 & 4 & 0 & 0 & 0 \\
Benchmark & 225 & 170 & 120 & 72 & 31 & 0 & 0 \\
Worst Case $(-10 \%)$ & $\infty$ & $\infty$ & 209 & 158 & 114 & 72 & 37 \\
\hline
\end{tabular}

Source: Own illustration

Based on table 4 it can be clearly observed that compared to the results shown in table 2 the effect of these negative jumps can result in delays on the investment of between 30 and 35 months in most cases. This is an important impact. It basically means that more EPF areas seem to be optimal for more immediate investments, however, they are negatively affected by the artificial control of residential energy rates in the months of April and October.

\section{Conclusion}

For this ROA setting, we have been able to determine a Californian households optimal decision time when choosing to invest in a residential solar PV System to obtain potential savings in their energy consumption. The choice has strong implications for the household. Entering this scheme is an irreversible decision that provides the household with uncertain savings implies an important and certain up-front investment. In order to be as realistic as possible, our model considers different scenarios for pricing that are believed to be conservative. From the household's perspective, reasoning is merely profit maximization, between the increasing prices of energy, 
given the discount rate and a technically immediate big investment required to trigger uncertain benefits. The household does not have an incentive to undertake the investment unless potential savings are high enough, as also explained by Schelly (2014) and Salm et al. (2016). For those households, the sooner they undertake it, the sooner they will start to save money but are in no rush. And in the best case, those savings are not clear enough that they would rush into their decision. Investment is always certain, and the outcome, although expected, is not.

Results of this study show that even though the potential of savings is clear, it might be optimal to wait somewhere in between 64 and 147 months ${ }^{10}$ in some cases, which is clearly a drawback. Important potential savings can be observed as long as the initial investment is not too high. We also observe that is precisely that initial investment in many cases what makes the delay in the investment to be so reasonable. As mentioned by Seel et al. (2014) projects can be twice as expensive in the United Estates than in Germany, and soft-costs are an important part of it. In reality subsidies and other incentives do not seem to be any longer a relevant component of the investment decision of Californian households, but they could be tuned to other relevant purposes, i.e. energy storage and panel recycling that could become the next big problem to solve in the realm of solar PV energy.

Regulators have an important part in order to promote more efficient markets for PV solar systems that are ultimately less costly to the Californian household. Current reforms such as the new tariffs imposed by the Federal government on the import of PV systems and components, along with estate level regulation regarding fixed monthly charges ${ }^{11}$ for residential electricity (discussed in the state of California at the time when this paper was written) could alter the evolution of PV system prices and electricity rates. Furthermore the artificial pricing of electricity rates, i.e. significant reductions every six months, have a deep impact on the optimal time of the investment decision according to the findings of this work.

\footnotetext{
${ }^{10}$ Approximately 5.5 and 12 years respectively.

${ }^{11}$ If implemented, this charges could set a floor price for energy limiting the potential of savings described in this work. Although currently on discussion, no fixed monthly charges are expected to be introduced before 2020 .
} 


\section{References}

Asiabanpour, B., Z. Almusaied, S. Aslan, M. Mitchell, E. Leake, H. Lee, J. Fuentes, K. Rainosek, N. Hawkes, and A. Bland (2017). Fixed versus sun tracking solar panels: an economic analysis. Clean Technologies and Environmental Policy 19(4), 1195-1203.

Ayompe, L. and A. Duffy (2013). Feed-in tariff design for domestic scale gridconnected PV systems using high resolution household electricity demand data. Energy Policy 61, 619-627.

Barbose, G. L., N. R. Darghouth, D. Millstein, K. H. LaCommare, N. DiSanti, and R. Widiss (2017). Tracking the Sun 10: The Installed Price of Residential and NonResidential Photovoltaic Systems in the United States. Technical report.

Bauner, C. and C. L. Crago (2015). Adoption of residential solar power under uncertainty: Implications for renewable energy incentives. Energy Policy 86, 27-35.

Bazilian, M., I. Onyeji, M. Liebreich, I. MacGill, J. Chase, J. Shah, D. Gielen, D. Arent, D. Landfear, and S. Zhengrong (2013). Re-considering the economics of photovoltaic power. Renewable Energy 53, 329-338.

Bollinger, B. and K. Gillingham (2012). Peer Effects in the Diffusion of Solar Photovoltaic Panels. Marketing Science 31(6), 900-912.

Botteron, P., M. Chesney, and R. Gibson-Asner (2003). Analyzing firms' strategic investment decisions in a real options' framework. Journal of International Financial Markets, Institutions and Money 13(5), 451-479.

Bull, P., N. Long, and C. Steger (2011). Designing Feed-in Tariff Policies to Scale Clean Distributed Generation in the U.S. The Electricity Journal 24(3), 52-58.

Candelise, C., M. Winskel, and R. J. Gross (2013). The dynamics of solar PV costs and prices as a challenge for technology forecasting. Renewable and Sustainable Energy Reviews 26, 96-107.

Castellanos, S., D. A. Sunter, and D. M. Kammen (2017). Rooftop solar photovoltaic potential in cities: How scalable are assessment approaches? Environmental Research Letters 12(12).

Chesney, M., J. Gheyssens, and B. Troja (2017). Market uncertainty and risk transfer in REDD projects. Journal of Sustainable Forestry 36(5), 535-553.

Drury, E., M. Miller, C. M. Macal, D. J. Graziano, D. Heimiller, J. Ozik, and T. D. Perry IV (2012). The transformation of southern California's residential photovoltaics market through third-party ownership. Energy Policy 42, 681-690. 
Dusonchet, L. and E. Telaretti (2010). Economic analysis of different supporting policies for the production of electrical energy by solar photovoltaics in western European Union countries. Energy Policy 38(7), 3297-3308.

Escribano, A., J. Ignacio Peña, and P. Villaplana (2011). Modelling electricity prices: International evidence. Oxford Bulletin of Economics and Statistics 73(5), 622-650.

Faiers, A. and C. Neame (2006). Consumer attitudes towards domestic solar power systems. Energy Policy 34(14), 1797-1806.

Fouquet, D. and T. B. Johansson (2008). European renewable energy policy at crossroadsFocus on electricity support mechanisms. Energy Policy 36(11), 4079-4092.

Frondel, M., N. Ritter, C. M. Schmidt, and C. Vance (2010). Economic impacts from the promotion of renewable energy technologies: The German experience. Energy Policy 38(8), 4048-4056.

Hopkins, A. S. (2017). The next energy economy. Science 356(6339), 709-709.

Hoppmann, J., J. Volland, T. S. Schmidt, and V. H. Hoffmann (2014). The economic viability of battery storage for residential solar photovoltaic systems A review and a simulation model. Renewable and Sustainable Energy Reviews 39, 1101-1118.

Huld, T., R. Müller, and A. Gambardella (2012). A new solar radiation database for estimating PV performance in Europe and Africa. Solar Energy 86(6), 1803-1815.

Kastner, I. and P. C. Stern (2015). Examining the decision-making processes behind household energy investments: A review. Energy Research \& Social Science 10, 7289.

Kim, K., H. Park, and H. Kim (2017). Real options analysis for renewable energy investment decisions in developing countries. Renewable and Sustainable Energy Reviews 75, 918-926.

Klein, M. and M. Deissenroth (2017). When do households invest in solar photovoltaics? An application of prospect theory. Energy Policy 109, 270-278.

Krupa, J. and L. D. Harvey (2017). Renewable electricity finance in the United States: A state-of-the-art review. Energy 135, 913-929.

Lam, P. T. and A. O. Law (2016). Crowdfunding for renewable and sustainable energy projects: An exploratory case study approach. Renewable and Sustainable Energy Reviews 60, 11-20.

Loubergé, H., S. Villeneuve, and M. Chesney (2002). Long-term risk management of nuclear waste: A real options approach. Journal of Economic Dynamics and Control 27(1), 157-180. 
Luthander, R., J. Widén, D. Nilsson, and J. Palm (2015). Photovoltaic selfconsumption in buildings: A review. Applied Energy 142, 80-94.

Mainzer, K., K. Fath, R. McKenna, J. Stengel, W. Fichtner, and F. Schultmann (2014). A high-resolution determination of the technical potential for residential-roofmounted photovoltaic systems in Germany. Solar Energy 105, 715-731.

Martin, N. and J. Rice (2018). Solar Feed-In Tariffs: Examining fair and reasonable retail rates using cost avoidance estimates. Energy Policy 112, 19-28.

Matisoff, D. C. and E. P. Johnson (2017). The comparative effectiveness of residential solar incentives. Energy Policy 108, 44-54.

Mazzucato, M. and G. Semieniuk (2018). Financing renewable energy: Who is financing what and why it matters. Technological Forecasting and Social Change 127, $8-22$.

$\mathrm{Ng}$, T. H. and J. Y. Tao (2016). Bond financing for renewable energy in Asia. Energy Policy 95, 509-517.

Pillai, U. (2015). Drivers of cost reduction in solar photovoltaics. Energy Economics 50, 286-293.

Rai, V. and S. A. Robinson (2015). Agent-based modeling of energy technology adoption: Empirical integration of social, behavioral, economic, and environmental factors. Environmental Modelling \& Software 70, 163-177.

Salm, S., S. L. Hille, and R. Wüstenhagen (2016). What are retail investors' risk-return preferences towards renewable energy projects? A choice experiment in Germany. Energy Policy 97, 310-320.

Schelly, C. (2014). Residential solar electricity adoption: What motivates, and what matters? A case study of early adopters. Energy Research \& Social Science 2, 183-191.

Seel, J., G. L. Barbose, and R. H. Wiser (2014). An analysis of residential PV system price differences between the United States and Germany. Energy Policy 69, 216226.

U.S. Department of Energy (2016). A Consumer's Guide. Get Your Power from theSun. Technical report.

U.S. Energy Information Administration (2018). Monthly Electric Power Industry Report.

Vaishnav, P., N. Horner, and I. L. Azevedo (2017). Was it worthwhile? Where have the benefits of rooftop solar photovoltaic generation exceeded the cost? Environmental Research Letters 12(9). 
Wang, P., L. Yuan, and A. T. H. Kuah (2017). Can a Fast-Expanding Market Sustain with Supply-Side Government Aid? An Investigation into the Chinese Solar Photovoltaics Industry. Thunderbird International Business Review 59(1), 103-114.

Wiser, R. H. (1997). Renewable energy finance and project ownership: The impact of alternative development structures on the cost of wind power. Energy Policy 25(1), 15-27.

Wolske, K. S., P. C. Stern, and T. Dietz (2017). Explaining interest in adopting residential solar photovoltaic systems in the United States: Toward an integration of behavioral theories. Energy Research \& Social Science 25, 134-151.

Wüstenhagen, R. and E. Menichetti (2012). Strategic choices for renewable energy investment: Conceptual framework and opportunities for further research. Energy Policy 40(1), 1-10.

Zhai, P., P. Larsen, D. Millstein, S. Menon, and E. Masanet (2012). The potential for avoided emissions from photovoltaic electricity in the United States. Energy 47(1), $443-450$. 


\section{Appendix}

\section{A Grid connected PV system}

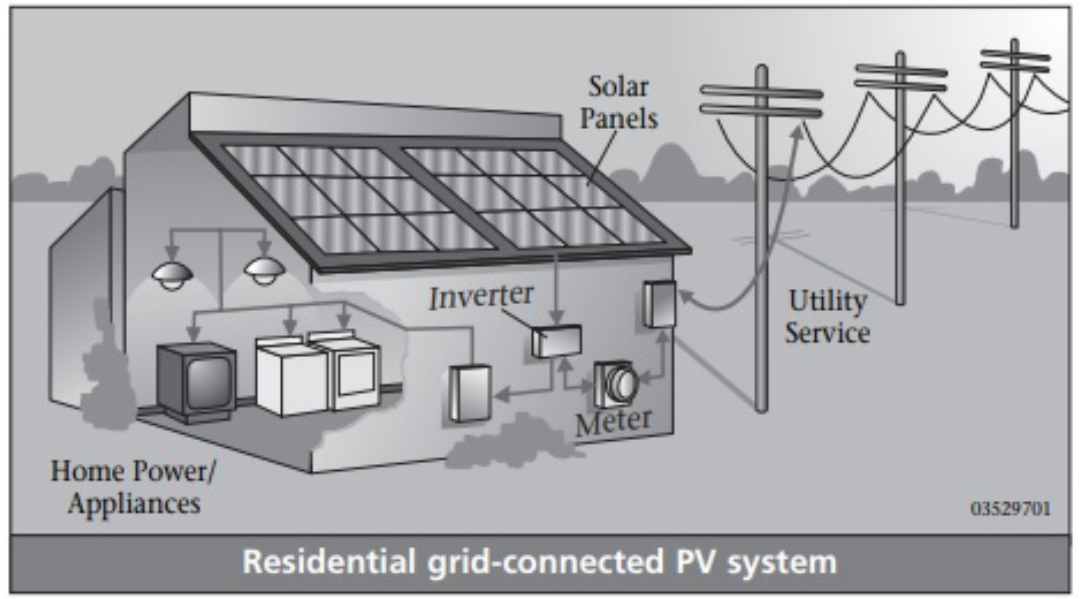

Figure 7: Diagram of a typical grid connected PV system. (U.S. Department of Energy, 2016)

\section{B Energy production factor (EPF)}

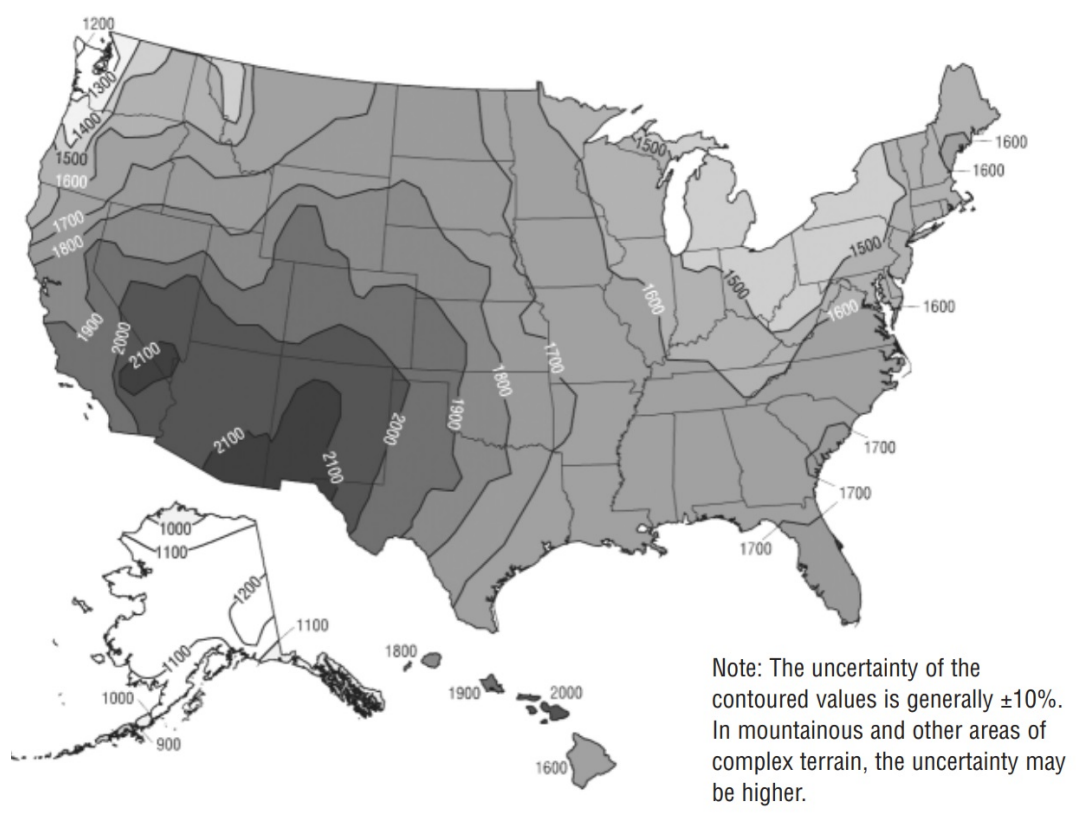

Figure 8: Energy production factor (EPF) by geographic area in the United States. (U.S. Department of Energy, 2016) 


\section{Cost of PV panel systems in California}

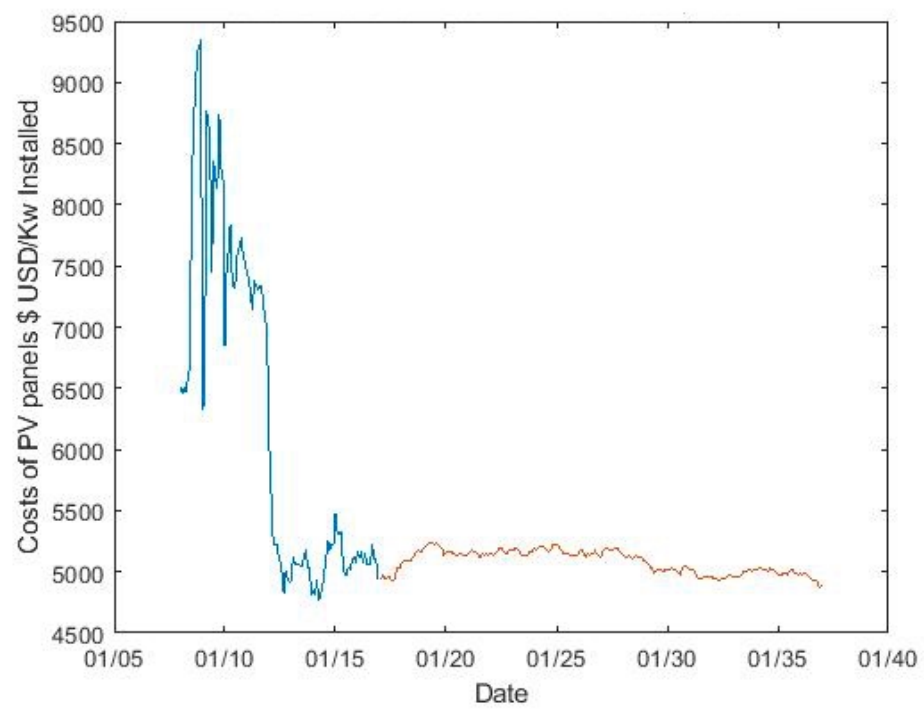

Figure 9: Actual and one simulated path of cost of PV panel systems to residential customers in California, per kW Installed, own illustration.

(U.S. Department of Energy, 2016)

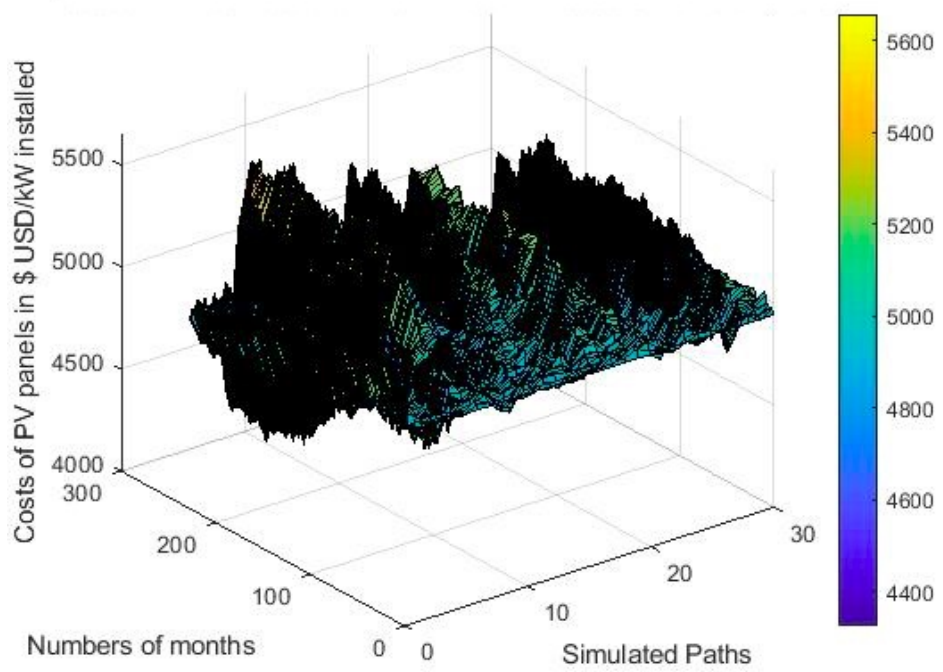

Figure 10: Multiple paths of simulations for cost of PV panels to residential customers in California, per $\mathrm{kW}$, first 30 paths of simulation, own illustration.

(U.S. Department of Energy, 2016) 


\section{Residential electricity rates in California}

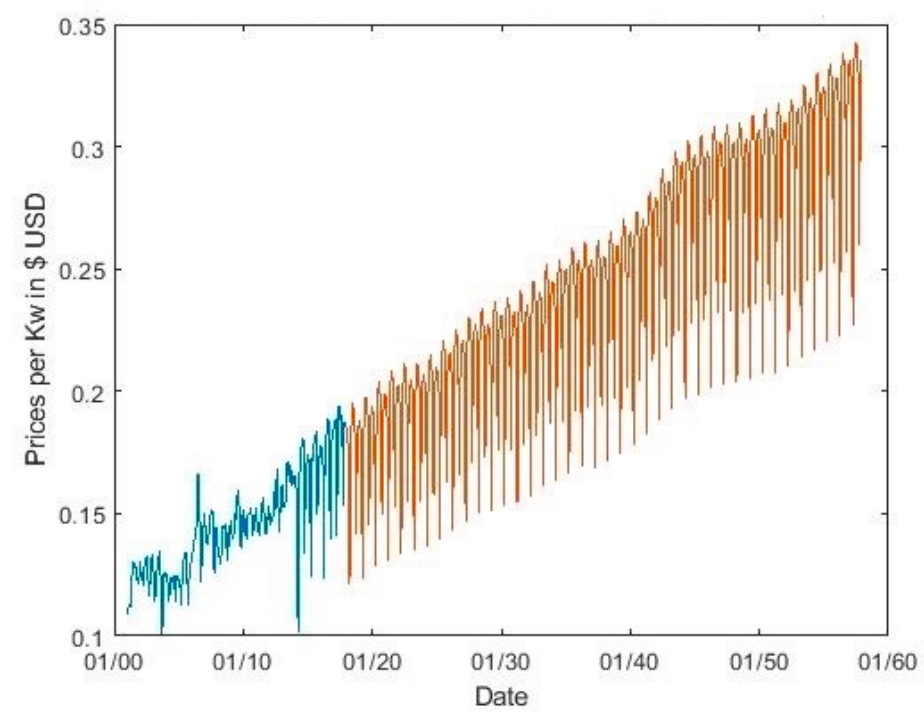

Figure 11: Actual and one path of simulated electricity rates to residential customers in California, own illustration.

(U.S. Energy Information Administration, 2018)

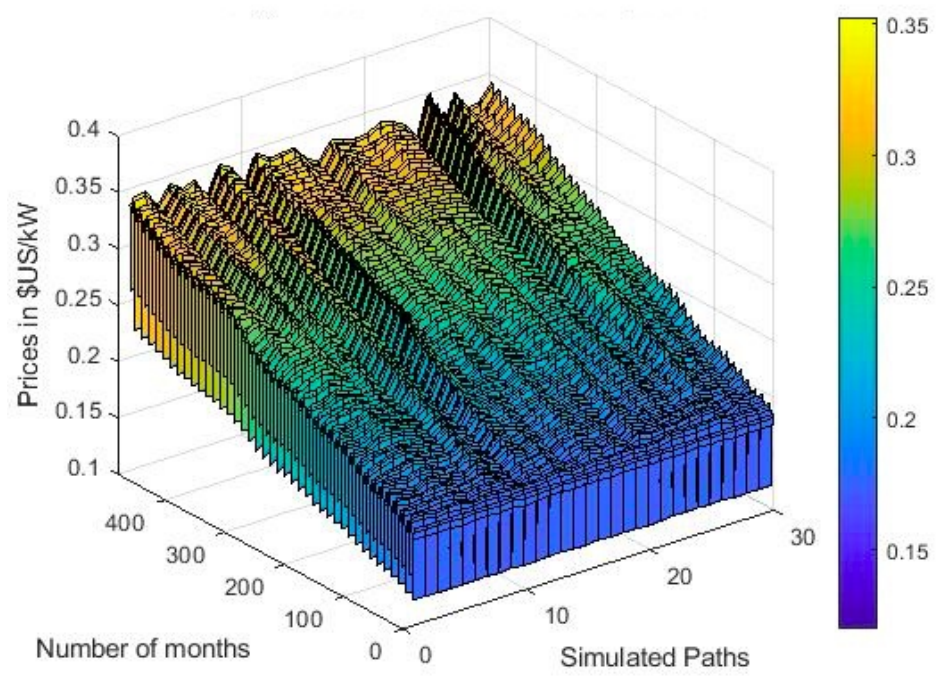

Figure 12: Multiple paths of simulations for electricity rates to residential customers, first 30 paths of simulation, own illustration.

(U.S. Energy Information Administration, 2018) 